\title{
A PRODUÇÃO DO CONHECIMENTO SOBRE FACEBOOK E EDUCAÇÃO NO PORTAL DE PERIÓDICOS DA CAPES: relatos de experiências docentes
}

\author{
Willian Lima Santos ${ }^{1}$ \\ Anne Alilma Silva Souza Ferrete2 \\ Manoel Messias Santos Alves 3
}

\section{RESUMO}

Com os avanços decorrentes da web 2.0, as interfaces que permitem interação e compartilhamento de conteúdos ganham novas funcionalidades que vão além do entretenimento. Nessa perspectiva, o Facebook, como rede social de maior destaque no mundo, pode estar alinhado a uma proposta pedagógica e servir como recurso didático, independentemente da modalidade de ensino. Nesse contexto, este estudo tem como principal objetivo refletir sobre o uso da plataforma do Facebook como recurso didático-pedagógico com foco na aprendizagem colaborativa. Trata-se de um estudo de cunho bibliográfico de natureza qualitativa, caracterizado pela construção de um estado da arte, em que serviram como fonte de pesquisa os artigos científicos disponíveis no Portal de Periódicos da CAPES publicados entre janeiro de 2014 e dezembro de 2018. Por meio das análises das produções acadêmicas, foi possível verificar um maior engajamento por parte dos docentes em relação à inserção de novas metodologias de ensino voltadas para o uso das TDIC na educação, aprimorando a comunicação e a interação entre discentes e docentes e, consequentemente, o aperfeiçoamento de um cenário virtual de aprendizagem e compartilhamento de dados.

Palavras-chave: Facebook. Educação. Recurso didático-pedagógico.

\footnotetext{
1 Mestrando em Educação pela Universidade Federal de Sergipe (PPGED/UFS). Pedagogo. Especialista em Tecnologias e Educação Aberta e Digital (UFRB). Pesquisador vinculado ao Núcleo de Pesquisa em Comunicação e Tecnologia (NUCA/UFS). Orcid iD: https://orcid.org/0000-0002-9298-1226. E-mail: willianjere@hotmail.com

2 Doutora em Educação pela Universidade Federal do Rio Grande do Norte (UFRN), Mestra em Educação pela Universidade Federal de Sergipe (UFS), Graduada na área de Tecnologia em Processamento de Dados pela Universidade Tiradentes (UNIT). Professora do Departamento de Educação (DED/UFS) e professora permanente do Programa de PósGraduação em Educação (PPGED/UFS). Líder do Núcleo de Pesquisa em Comunicação e Tecnologia (NUCA/UFS). Orcid iD: https://orcid.org/0000-0001-9637-6616. E-mail: alilma.ferrete50@gmail.com

3 Doutorando em Educação (PPGED/UFS). Mestre em Ensino de Ciências e Matemática (PPGECIMA/UFS). Bacharel em Enfermagem (AGES); Especialista em Saúde da Família (UFPEL). Pesquisador vinculado ao Núcleo de Pesquisa em Comunicação e Tecnologia (NUCA/UFS). Orcid iD: https://orcid.org/0000-0002-4070-1691. E-mail: messyarts@hotmail.com
} 


\title{
THE PRODUCTION OF FACEBOOK KNOWLEDGE ABOUT FACEBOOK AND EDUCATION AT PORTAL DE PERIÓDICOS DA CAPES: professors experience
}

\author{
reports
}

\begin{abstract}
Due to the advances of Web 2.0, interfaces that allow interaction and contents sharing, acquire new functions besides the entertainment. In this perspective, Facebook as Social Network is highlighted and may be aligned to a new pedagogical purpose, serving as didactical resource, independently of the teaching model. This study has a main objective to reflect about the use of Facebook Platform as Didactic Pedagogical Interface focusing on collaborative learning. It's all about a bibliographic qualitative nature study, characterized by the construction of a state of Art, have had as basis the source of scientific available articles at Capes journals published between January 2014 to 2018. Throughout the analysis of the academic productions was possible to verify a major work by the Professors regarded to the engagement of the new teaching methodologies related to the use of TDIC in education, improving the communication between students and Professors and consequently making things better for a virtual learning scenario and data sharing for educative use.
\end{abstract}

Keywords: Facebook. Education. Didactic-pedagogical resource.

\section{LA PRODUCCIÓN DE CONOCIMIENTOS Y EDUCACIÓN DE FACEBOOK EN EL PORTAL DE REVISTAS DE CAPES: informes de experiencias docentes}

\section{RESUMEN}

Conlos avances que vienenconla web 2.0, las interfaces que permitenlainteracción y el intercambio de contenidoobtienennuevas funcionalidades más allá del entretenimiento. Desde esta perspectiva, Facebook, como la red social más destacada del mundo, puede estar alineada con una propuesta pedagógica y servir como un recurso didáctico, independientemente de la modalidad de enseñanza. Este estudio tiene como objetivo reflexionar sobre el uso de la plataforma de Facebook como una interfaz didáctico-pedagógica centrada en el aprendizaje colaborativo. Este es un estudio bibliográfico cualitativo, caracterizado por la construcción de un estado del arte Los artículos científicos disponibles en el portal de la revista CAPES publicados entre enero de 2014 y diciembre de 2018 sirvieron como fuentes de investigación. Al analizar las producciones académicas, fue posible verificar un mayor compromiso por parte de los docentes con respecto a la inserción de nuevas metodologías de enseñanza centradas en el uso de las TIC en la educación, mejorando la comunicación e interacción entre estudiantes y docentes $y$, en consecuencia, la mejora de un escenario aprendizaje virtual y uso compartido de datos.

Palabras clave: Facebook Educación. Recurso didáctico-pedagógico. 


\section{INTRODUÇÃO}

Este estudo tem como objetivo geral refletir sobre o uso do Facebook como recurso didático-pedagógico, partindo do ponto de vista dos relatos de experiência, das observações participantes e dos estudos de pesquisadores que realizaram trabalhos de campo na área da educação, com ênfase na inclusão digital em suas práticas docentes, e que apostaram nessa rede social como elemento educacional.

Como objetivos específicos, este estudo procurou descrever as ferramentas existentes na plataforma da rede social Facebook e como poderiam ser utilizadas para fins educacionais; levantar os pontos de vantagem e desvantagem do seu uso como recurso educacional; e compreender o uso dessa rede social na sala de aula como uma prática que pode contribuir para a inclusão digital no contexto educacional.

Trata-se de um estudo bibliográfico de caráter qualitativo que se utilizou, como fonte de pesquisa, das produções disponíveis no banco de dados da CAPES (Coordenação de Aperfeiçoamento de Pessoal de Nível Superior), considerando os últimos cinco anos de publicação, correspondentes a janeiro de 2014 a dezembro de 2018. Além do levantamento das produções, sentiu-se a necessidade de construir um breve contexto histórico dessa rede social, assim como uma análise das ferramentas existentes na própria página do Facebook e de como elas poderiam ser utilizadas para fins pedagógicos.

Com o advento e o desenvolvimento da web 2.0, emergiram um novo olhar e uma outra concepção para a educação no que diz respeito ao uso de recursos tecnológicos e midiáticos, considerando o momento em que a internet possibilitou a interação entre os usuários, visando à construção e ao compartilhamento de informações. A forma de se comunicar foi potencializada e estruturada por meio de plataformas online; assim, a distância entre os sujeitos na educação não é mais um obstáculo. Agora, a preocupação está centrada na utilização desses recursos tecnológicos e midiáticos da web com finalidades pedagógicas, uma vez que a inserção 
das TDIC na sala de aula tem se caracterizado como um enorme desafio a ser enfrentado pelos docentes.

Dessa forma, refletir sobre o processo de ensino e aprendizagem mediado pelas TDIC (Tecnologias Digitais da Informação e Comunicação) nos faz também pensar nas características dos novos meios de interação que estão associados à participação e à mediação colaborativa. Nessa perspectiva, concebemos 0 Facebook como plataforma digital de comunicação que, atrelada a objetivos pedagógicos, pode contribuir significativamente para o andamento do processo de ensino-aprendizagem, considerando as diferentes ferramentas disponíveis na web e suas funcionalidades que podem se tornar pedagógicas, mesmo diante de um cenário virtual de aprendizagem informal.

Essa rede social tem contribuído cada vez mais para o compartilhamento de ideias e inovações, dispondo de ferramentas que permitem a criação de comunidades de aprendizagem, grupos privados, chat, videoconferência, compartilhamento de materiais em anexos e arquivos de mídia (vídeo, áudio, música, podcasts), entre outras numerosas possibilidades de interação por meio de links diversos e websites, sendo possível também construir enquetes, debates, questionários.

Entretanto, o uso dessa ferramenta no âmbito educacional ainda está significativamente condicionado à forma como o professor se relaciona e percebe o uso das TDIC, algo que pode estar diretamente ligado à dificuldade de utilizar recursos das ferramentas que existem dentro da Plataforma do Facebook, ou por não adotarem metodologias capazes de direcionar a atenção do aluno dentro do espaço virtual.

A escolha dessa temática justifica-se pela ausência de abordagens significativas nos cursos de formação de professores no que diz respeito ao uso das novas tecnologias digitais da comunicação e informação (TDIC), assim como à dificuldade em adaptação dos espaços online, no caso o Facebook, como ferramenta pedagógica para a construção do processo de ensino e aprendizagem, mesmo se tratando de um espaço online de 
comunicação informal, mas que passa a ser percebido como aliado ao processo educacional, desde que esteja entrelaçado ao planejamento didático e alinhado aos objetivos estabelecidos pelo professor, aspirando à construção da aprendizagem de forma colaborativa.

Por meio desta pesquisa, almejamos fornecer mais informações no que diz respeito ao uso do Facebook, como ferramenta que pode ser aliada ao processo de ensino-aprendizagem, para que se possam romper paradigmas tradicionais que excluem do contexto escolar plataformas de interação online, e assim restringindo o uso das tecnologias digitais de informação e comunicação. Logo, é preciso considerar a necessidade dos cursos de formação continuada no sentido de que sejam capazes de preparar os professores (imigrantes digitais) para a sua clientela de alunos (nativos digitais).

O presente trabalho está estruturado em quatro seções: a primeira, referente à introdução da pesquisa, em que se buscou apresentar o tema, os objetivos e a metodologia utilizada na construção do referido estudo; a segunda seção é o resultado de um breve contexto histórico sobre a rede social Facebook; na terceira seção, será apresentada a produção do conhecimento sobre Facebook e Educação que foi levantada a partir do Portal de Periódicos da CAPES, sendo que tal seção contém uma subseção sobre as ferramentas disponíveis nessa rede social, abordando suas vantagens e desvantagens para o ensino. Já na quarta e última seção, estão as considerações finais da pesquisa.

\section{BREVE CONTEXTUALIZAÇÃO HISTÓRICA DO FACEBOOK}

Criado em fevereiro 2004, por Mark Zuckerberg, Dustin Moskovitz e Chris Hugher, alunos do curso de computação da Universidade de Harvard, era apenas uma simples rede social de caráter restritivo, com o nome original de Facemash, que objetivava somente configurar um espaço virtual no qual as pessoas podiam encontrar umas às outras, compartilhando opiniões e momentos por meio de fotografias (TEIXEIRA, 2012). 
No início, essa rede social foi condicionalmente limitada para uso apenas dos estudantes de Harvard, mas, com os avanços e o apoio financeiro de outras instituições, o uso foi sendo propagado para outras faculdades na área de Boston, da Ivy League e da Universidade Stanford. Logo, vários circuitos universitários que foram convidados a fazer parte dessa rede estavam integrados, e, em 2005, a plataforma possuía mais de cinco milhões de usuários ativos e, nesse mesmo ano, passou a ser conhecida como Facebook, sendo também oficialmente inaugurada.

Em 2006, a plataforma passou a oferecer acesso liberado a qualquer pessoa acima da faixa etária de 13 anos que fornecesse informações simples para cadastro, como nome, data de nascimento, e-mail ou número de telefone celular atualizado, assim como gênero (homem ou mulher), além de - usuário inicialmente aceitar as políticas da empresa Facebook para a adesão à sua plataforma virtual.

No ano de 2011, essa rede social se destacou por alcançar o ranking de maior servidor de fotos do mundo, tornando-se popular inicialmente entre os jovens, mas vem ao longo dos anos revolucionando gerações. A facilidade e o alcance do compartilhamento são a sua principal característica, permitindo instantaneamente a troca de informações nos variados formatos de mídia.

De acordo com Teixeira (2012), o Facebook é a rede social que se tornou a mais popular da história, seu nome originou-se por meio do apelido de um livro de caráter artesanal que passava pela calourada, de mão em mão, no âmbito das instituições americanas de ensino superior e que tinham como intuito que esses alunos passassem a conhecer seus colegas (veteranos) da instituição, com informações básicas como nome, curso e fotos dos estudantes.

Em sua página oficial, o Facebook (2019) afirma que sua missão social é "dar às pessoas o poder de criar comunidades e aproximar o mundo". Aparentemente, os estudos apontam que essa missão vem sendo cumprida numa extrema proporção; nas pesquisas realizadas pela úNICO Agência 
Digital, que desde 2009, realiza levantamento de dados estatísticos sobre a expansão das redes sociais, o Facebook aparece mais forte do que nunca, como podemos observar no mapa da Figura 01, sendo representado pela cor azul. Nos dias atuais, continua sendo a principal rede social em 153 dos 167 países analisados (92\% do planeta), considerando a existência dos 193 países contabilizados pela Organização das Nações Unidas (ONU).

Figura 01 - Mapa do mundo das redes sociais WORLD MAP OF SOCIAL NETWORKS

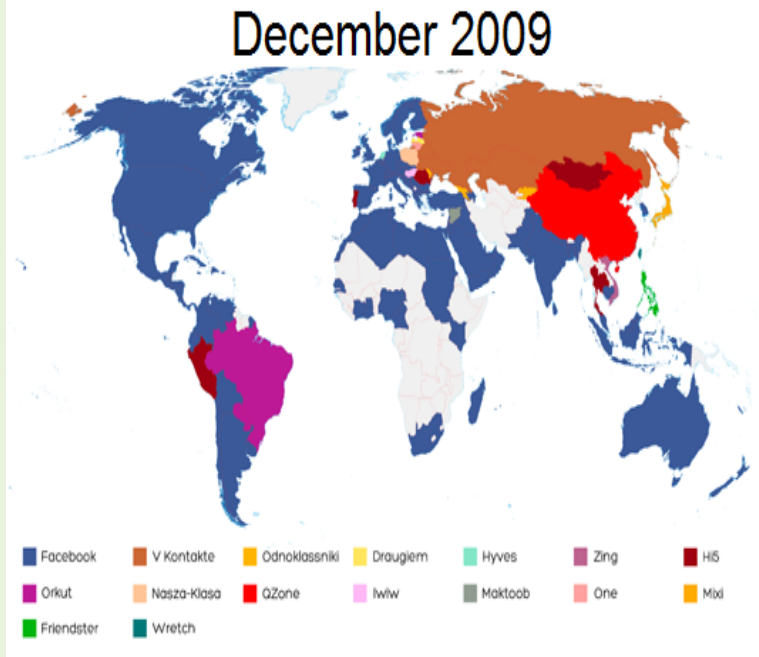

Fonte: Agência Único - disponível em https://vincos.it/world-map-of-social-networks/.

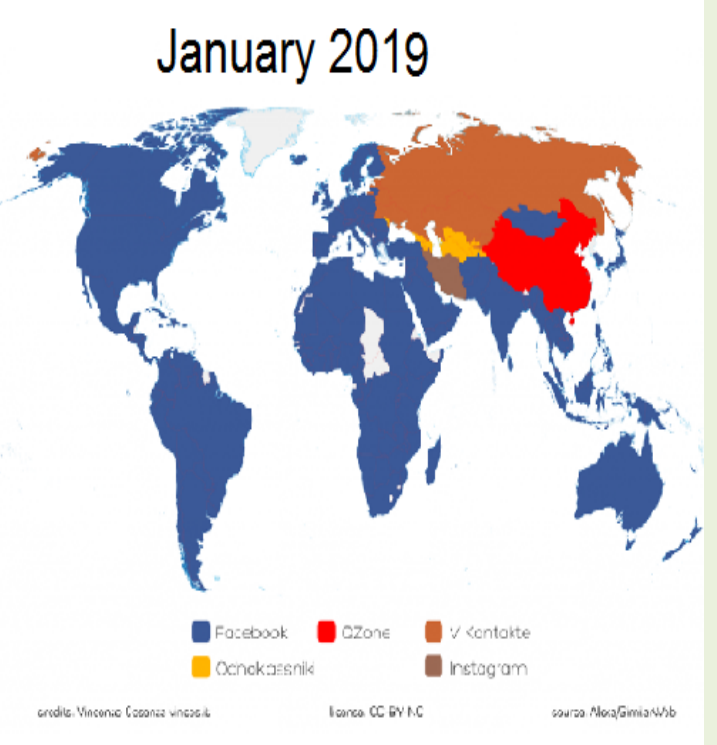
January 2019

De acordo com esse gráfico, é possível perceber que o Facebook, enquanto plataforma digital de interação e comunicação estabeleceu-se no primeiro lugar do ranking como maior rede social com números de usuários ativos do mundo. Talvez, sua facilidade de acesso, além do uso gratuito e da praticidade na troca de informações entre seus usuários, tenham sido as causas de tamanha repercussão e adesão da plataforma ao longo dos últimos anos. 
Os utilizadores partilham diariamente quatro bilhões de unidades de conteúdo, incluindo uploads ${ }^{4}$ de 250 milhões de fotografias, estando o Facebook atualmente integrado a mais de nove milhões de websites e aplicações. Logo, integração é a principal característica dessa rede social, uma vez que permite a introdução de links que direcionam os usuários para outras plataformas, páginas da web, sites, blogs, aplicativos, jogos, enquetes etc.

[...] a característica que mais diferencia o Facebook das demais redes sociais é a sua plataforma, pois permite que outros websites e aplicações se integrem no Facebook através de uma linguagem aberta, denominada de Open Graph (CORREIA e MOREIRA, apud GJOKA et al. 2008 sd).

Essa interatividade em longa escala tem despertado novas funcionalidades para a rede social, tanto para 0 marketing comercial quanto para a educação, sendo esse último o foco deste trabalho. As TDIC e seus constantes avanços vêm cada vez mais revolucionando a forma como se ensina e se aprende na perspectiva do ciberespaço. E os dispositivos móveis estão contribuindo significativamente para essa expansão da conexão em larga escala.

Nesse contexto, destacamos a relevância do Facebook como ferramenta de comunicação informal, mas que pode ser utilizada com finalidade pedagógica, objetivando a interligação da relação professoraluno na perspectiva de um espaço virtual capaz de promover aprendizagem. As interações precisam ser mediadas pelo professor, e o acompanhamento pedagógico é crucial nesse processo de comunicação online, para que os alunos não fiquem dispersos diante de tantas informações que estão na rede.

Santos e Santos (2017) destacam que, por meio do uso da tecnologia, há uma intensa objetividade em facilitar a compreensão do aluno, fazendo uso de uma linguagem acessível e interativa. Do ponto de vista dos autores,

\footnotetext{
4 Termo da língua inglesa com significado referente à ação de enviar dados de um dispositivo local para outros servidores remotos através da internet. Envio de dados para o ciberespaço.
}

Revista Exitus, Santarém/PA, Vol. 10, p. 01 - 28, e020031, 2020. 
esses recursos tendem a objetivar a forma como se aprende e se ensina mediado pelas TIC. Entretanto, esse envolvimento entre tecnologia e educação tem se caracterizado como um problema para boa parte dos professores que atuam na Educação Básica, ao passo que outros as percebem - as TIC - como recursos que facilitam a forma de ensinar, discussão que veremos nos próximos tópicos deste estudo.

\section{ESTADO DA ARTE: o facebook como recurso pedagógico}

Nas últimas décadas, tem se produzido significativamente um conjunto de pesquisas intituladas de "estado da arte" ou "estado do conhecimento", também definidas como pesquisas de cunho bibliográfico, as quais buscam fazer o mapeamento e o levantamento de discussões sobre determinada produção acadêmica (FERREIRA, 2002).

Considerando os últimos cinco anos das produções publicadas no Portal de Periódicos da CAPES, no período de janeiro de 2014 a dezembro de 2018, foi possível verificar que até o momento estão disponíveis em língua portuguesa 217 estudos que traçam um elo entre Facebook e educação nas diferentes modalidades (Educação Infantil, Ensino Fundamental, Ensino Superior, Educação a Distância, Educação Profissional - Ensino Técnico).

Quanto aos descritores utilizados para a escolha dos estudos que seriam analisados neste trabalho, precisavam se atender as seguintes características: estarem escritos em língua portuguesa, contemplarem relatos de experiências e se enquadrarem no recorte temporal definido na pesquisa $-2014-2018$.

Os dados que foram levantados referentes ao uso do Facebook como recurso pedagógico foram colhidos por meio dos resumos dos periódicos que mais se enquadraram na perspectiva educacional, no que diz respeito às possibilidades de uso dessa plataforma virtual a favor do processo de ensino-aprendizagem. Nessa perspectiva, selecionamos 15 trabalhos que apresentavam relatos de experiências que serviram como base de pesquisa; inicialmente, os artigos foram organizados em ordem cronológica, com 
dados dos autores e suas principais contribuições, como podemos observar no quadro 01 . Posteriormente, foram acrescentadas mais informações acerca dos relatos de experiência de cada produção.

Quadro 01: Artigos com relatos de experiência Facebook e educação

\begin{tabular}{|c|c|c|}
\hline Autor & Título da obra & Contribuição \\
\hline $\begin{array}{l}\text { Santos et al. } \\
(2014)\end{array}$ & $\begin{array}{l}\text { Utilização de grupos de rede } \\
\text { social como ferramenta didática } \\
\text { no curso de engenharia de } \\
\text { produção. }\end{array}$ & $\begin{array}{l}\text { Demonstra como a interatividade em } \\
\text { rede pode contribuir para a efetivação } \\
\text { do processo de ensino-aprendizagem. }\end{array}$ \\
\hline $\begin{array}{l}\text { Ferreira e } \\
\text { Campos } \\
\text { (2014) }\end{array}$ & \begin{tabular}{llr} 
Facebook & e & \multicolumn{2}{c}{ recursos } \\
educacionais & abertos & na \\
formação de pesquisadores em & em \\
educação: & percepções & ercon \\
reflexões. & &
\end{tabular} & $\begin{array}{l}\text { - Percepção do Facebook como } \\
\text { espaço de formação. }\end{array}$ \\
\hline $\begin{array}{l}\text { Silva et al. } \\
\text { (2015) }\end{array}$ & $\begin{array}{l}\text { A Construção do Conhecimento } \\
\text { via Facebook: análise de um } \\
\text { projeto de ensino de geografia. }\end{array}$ & $\begin{array}{l}\text { - Projeto em rede. } \\
\text { - Uso das ferramentas de } \\
\text { geolocalização do próprio Facebook. }\end{array}$ \\
\hline $\begin{array}{l}\text { Tonetto e } \\
\text { Tonini (2015) }\end{array}$ & $\begin{array}{l}\text { Ensinar e aprender geografia } \\
\text { com/nas redes sociais. }\end{array}$ & $\begin{array}{l}\text { - Observação das paisagens para } \\
\text { análise dos aspectos geográficos. }\end{array}$ \\
\hline $\begin{array}{l}\text { Domingues } \\
\text { e Vieira } \\
\text { (2016) }\end{array}$ & $\begin{array}{l}\text { Utilização da rede social } \\
\text { Facebook em sala de aula. }\end{array}$ & $\begin{array}{l}\text { - Inclusão digital com foco na } \\
\text { inovação tecnológica na sala de aula. }\end{array}$ \\
\hline $\begin{array}{l}\text { Rabelo e } \\
\text { Tavares } \\
\text { (2016) }\end{array}$ & $\begin{array}{l}\text { As tecnologias digitais no ensino e } \\
\text { aprendizagem de línguas. }\end{array}$ & $\begin{array}{l}\text { - Acompanhamento de } \\
\text { comunicações em rede, seja no } \\
\text { mesmo idioma ou não, através da } \\
\text { ferramenta de tradução. }\end{array}$ \\
\hline $\begin{array}{l}\text { Oliveira } \\
(2016)\end{array}$ & $\begin{array}{l}\text { Mediação docente e distância } \\
\text { transacional: uso do Facebook } \\
\text { num mestrado em regime misto } \\
\text { (B-learning). }\end{array}$ & $\begin{array}{l}\text { - Uso da rede social na EAD, } \\
\text { ultrapassando os limites do AVA. }\end{array}$ \\
\hline $\begin{array}{l}\text { Francisco e } \\
\text { Oliveira } \\
\text { (2016) }\end{array}$ & $\begin{array}{l}\text { Práticas pedagógicas digitais: o } \\
\text { Facebook e a sala de aula } \\
\text { invertida na formação dos alunos } \\
\text { do ProfLetras. }\end{array}$ & $\begin{array}{l}\text { - Inserção de metodologias ativas. } \\
\text { - Inclusão digital e tecnológica. } \\
\text { - Aprimoramento de técnicas docentes } \\
\text { e de pesquisa (Mestrado Profissional). }\end{array}$ \\
\hline $\begin{array}{l}\text { Neves } \\
\text { (2017) }\end{array}$ & $\begin{array}{l}\text { BiblioJuris - Biblioteconomia e } \\
\text { Direito: o uso do Facebook na } \\
\text { educação continuada }\end{array}$ & $\begin{array}{l}\text { - Utilização de rede social como } \\
\text { espaço de interatividade em cursos de } \\
\text { formação continuada. }\end{array}$ \\
\hline $\begin{array}{l}\text { Costa e } \\
\text { Castilho } \\
\text { (2017) }\end{array}$ & $\begin{array}{l}\text { Contribuições do Facebook para } \\
\text { a alfabetização matemática no } \\
\text { 3. ano do ensino fundamental. }\end{array}$ & $\begin{array}{l}\text { - Aprendizagem lúdica. } \\
\text { - Inclusão digital no ambiente escolar. }\end{array}$ \\
\hline $\begin{array}{l}\text { Torres et al. } \\
\text { (2017) }\end{array}$ & $\begin{array}{l}\text { Exposição fotográfica e uso do } \\
\text { Facebook para fins educacionais. }\end{array}$ & $\begin{array}{l}\text { Demonstra as possibilidades do uso } \\
\text { dessa rede social para fins educativos } \\
\text { por meio do compartilhamento de } \\
\text { dados (fotos). }\end{array}$ \\
\hline $\begin{array}{l}\text { Tomio et al. } \\
(2018)\end{array}$ & $\begin{array}{l}\text { Professor@ facebookeir@ e seu } \\
\text { desenvolvimento profissional } \\
\text { docente em um contexto } \\
\text { informal. }\end{array}$ & $\begin{array}{l}\text { Demonstra como uma rede social } \\
\text { pode auxiliar o desenvolvimento do } \\
\text { professor, mesmo sendo um espaço de } \\
\text { interação informal. }\end{array}$ \\
\hline Policarpo e & Prof., posso usar o Facebook?: & Estrutura um espaço acadêmico que \\
\hline
\end{tabular}




\begin{tabular}{|l|l|l|}
\hline $\begin{array}{l}\text { Bergmann } \\
(2018)\end{array}$ & $\begin{array}{l}\text { experiência de integração de } \\
\text { mídias sociais em classe. }\end{array}$ & $\begin{array}{l}\text { seja propício para a integração de } \\
\text { uma rede social como recurso } \\
\text { pedagógico. }\end{array}$ \\
\hline $\begin{array}{l}\text { Oliveira } \\
\text { (2018) }\end{array}$ & $\begin{array}{l}\text { Sala de aula invertida nas aulas } \\
\text { de matemática na formação do do } \\
\text { pedagogo em tempos de } \\
\text { cibercultura. }\end{array}$ & $\begin{array}{l}\text { Enfatiza o uso de uma metodologia } \\
\text { ativa de ensino, com foco no aluno } \\
\text { como protagonista de sua } \\
\text { aprendizagem. }\end{array}$ \\
\hline
\end{tabular}

Fonte: Os autores.

Na perspectiva da cultura digital, Pierre Lèvy (2010, p. 159) afirma que "qualquer reflexão sobre o futuro dos sistemas de educação e de formação na cibercultura deve ser fundada em uma análise prévia da mutação contemporânea da relação com o saber".

Com o crescente avanço da educação aberta, digital e online ao alcance de todos, surgem percepções de comunidades de aprendizagem que extrapolam a permanência dentro de um único ambiente virtual, originando os novos Cenários de Aprendizagem, que em sua maioria são interfaces disponíveis na web, como blogs, sites, aplicativos, redes sociais. São espaços de interação informal que não foram criados com finalidade pedagógica, muito menos carregam em sua essência a intenção de educar, uma vez que eram vistos apenas como espaços para bate-papo, postagens diversas, marketing industrial. Suas únicas finalidades expressas seriam o lazer, o entretenimento e o comércio.

Corroborando as ideias de Levy (2010), Perrenoud (2000) enfatiza sobre as mudanças ocorrentes no modelo educacional, considerando que a sociedade mudou, e a escola, como espaço catalisador de formação cidadã, precisa acompanhar as mudanças. Logo, inserir recursos tecnológicos no âmbito escolar é umas das competências necessárias ao docente, de acordo com o mesmo autor. E é nessa perspectiva que trataremos a plataforma do Facebook como espaço online de interação capaz de promover aprendizagem e que pode ser utilizado como ferramenta de suporte pedagógico.

Nesse sentido, Barros et al. $(2013$, p. 81$)$ afirmam que: 
[...] a educação na rede exige, atualmente, que se equacione o processo pedagógico de forma diferente. No entanto, a mudança não deve ser vista só do ponto de vista tecnológico, mas, sobretudo, em termos de mentalidade e de prática. Esta realidade implica uma alteração cultural, pois obriga a repensar os papéis dos educadores e dos estudantes, e a relação existente entre eles, para além das implicações em nível da planificação de cursos e currículos.

Alguns pesquisadores focam nessa plataforma como espaço de promoção de comunicação que pode aproximar o diálogo entre professor e aluno. Nessa perspectiva, Santos et al. (2014) em seu estudo trataram da relevância dos grupos virtuais que são criados em redes sociais, em especial o Facebook, como uma ferramenta didática que deve ser utilizada com o intuito de facilitar a comunicação. Trata-se de um estudo de caso realizado com os alunos do curso de Engenharia de Produção da Universidade Federal da Grande Dourados (UFGD), no âmbito de quatro disciplinas em que os docentes faziam uso desse recurso tecnológico com finalidades pedagógicas.

Ferreira e Campos (2014) discutiram a integração dessa plataforma informal como recurso pedagógico numa disciplina presencial em curso de pós-graduação stricto sensu. A análise buscou compreender a experiência por meio das postagens que foram compartilhadas por 14 alunos durante 0 semestre letivo, além dos diálogos conduzidos pelo docente. A discussão está centrada no uso do site, nas percepções em relação a essa integração na educação, na forma como as atividades online podem ser desenvolvidas e nos desafios associados ao seu uso.

Outros autores apostam na aprendizagem colaborativa, ou seja, o aluno, mesmo estando no virtual, precisa perceber que a aprendizagem nesse espaço ocorre em conjunto, por meio da partilha de dados. Silva et al. (2015) analisaram em seu estudo o comportamento de alunos do $3^{\circ}$ ano durante as aulas de Geografia, em sala de tecnologia educacional, numa escola pública. O foco estava no uso do Facebook na construção do conhecimento de forma colaborativa. Essa pesquisa é fruto da junção desenvolvida pela escola, em parceria com alunos-estagiários de iniciação 
à docência, bolsistas do PIBID/EaD/UFGD. A partir de tal estudo, foi possível constatar que o uso dessa plataforma mostrou ter potencial significativo como ferramenta pedagógica, se bem aplicada.

Nessa perspectiva de utilização de recursos tecnológicos, Perrenoud (2000) ressalta a necessidade de implementação na ação docente como elemento indispensável. Para ele,

Formar para as novas tecnologias é formar o julgamento, o senso crítico, o pensamento hipotético e dedutivo, as faculdades de observação e de pesquisa, a imaginação, a capacidade de memorizar e classificar, a leitura e a análise de textos e de imagens, a representação de redes, de procedimentos e de estratégias de comunicação (PERRENOUD, 1999, p. 128).

Utilizar o recurso de localização, integrado às redes sociais, pode ser uma boa estratégia para análises geográficas. Tonetto e Tonini (2015) enfatizaram sobre a relevância das redes sociais online e suas potencialidades na perspectiva do ensino de Geografia. Propõem, por meio desse estudo, uma reflexão crítica na forma como essas ferramentas de localização (GPS) que estão inseridas dentro da plataforma do Facebook podem contribuir para a construção da aprendizagem geográfica, traçando uma conexão entre o ciberespaço (espaço virtual) e o espaço físico, no caso a escola. Quanto à abordagem desse estudo, é construído nas trilhas das pesquisas pós-críticas em educação.

A plataforma é percebida como o lócus para analisar as formas de comunicação e interação entre os sujeitos construtores da aprendizagem. Quanto aos resultados dessa prática, os autores concluíram que:

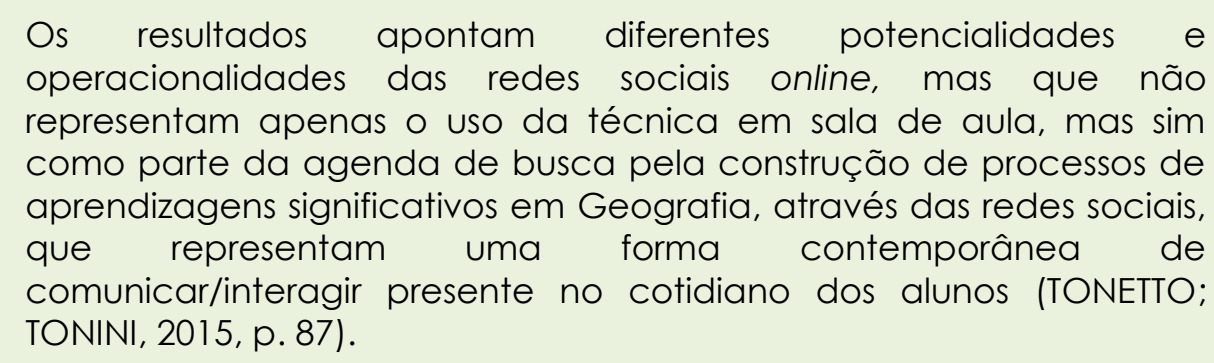

Quanto à inserção das redes sociais no contexto escolar, Domingues e Vieira (2016) em seu estudo, intitulado "Utilização da rede social Facebook 
em sala de aula", trataram da inserção das Tecnologias de Informação e Comunicação (TIC) no contexto escolar, observando a relação entre nativos e imigrantes digitais na perspectiva da cultura digital. De acordo com os autores, o trabalho nasce a partir do questionamento de um aluno do $6^{\circ}$ ano do Ensino Fundamental. A indagação tratava-se do fato de os professores não se utilizarem do Facebook no desenvolvimento de suas aulas. O estudo foi realizado por meio de uma análise bibliográfica, contextualizando a rede social, com a descrição de características e ferramentas que podem ser utilizadas a favor do processo de ensino-aprendizagem.

Oliveira (2016) em seu estudo abordou o uso do Facebook como recurso pedagógico, na perspectiva de um mestrado em regime misto, apresentando o professor como mediador do processo de ensinoaprendizagem, além de suscitar e orientar que os alunos estejam engajados na colaboração. E, para essa colaboração, faz-se necessário o uso da interação, e, para isso, utilizou-se da rede social, como podemos perceber no trecho abaixo, em fragmento retirado de sua obra.

[...] lecionação num curso de mestrado acadêmico em Educação que funciona em regime b-learning e no qual foi usado o Facebook, para além da plataforma institucional, como fórum de discussão e espaço de partilha de trabalhos e sensibilidades (OLIVEIRA, 2016, p. 1484).

Rabelo e Tavares (2016), por meio de um estudo exploratório, investigaram as percepções dos alunos do ensino superior quanto à utilização do Facebook como espaço complementar para as aulas presenciais de língua estrangeira. Diante das análises provenientes do levantamento do estado da arte, foi possível considerar que grupos criados nas redes sociais contribuem efetivamente para a construção de aprendizagem colaborativa entre os sujeitos participantes, ampliando o canal de diálogo e interação entre professor, estudantes e conteúdo.

Francisco e Oliveira (2016) objetivaram discutir sobre a importância da sala de aula invertida nos processos pedagógicos em um programa de pósgraduação (ProfLetras), considerando um novo modelo que impulsiona a 
aprendizagem colaborativa. Conceberam a plataforma Facebook como um ambiente propício para a mediação docente, direcionando o caminho para a construção de uma aprendizagem coletiva e se caracterizando como uma forma híbrida, mas que não destitui o modelo tradicional de aula.

Costa e Castilho (2017), por meio de um estudo de natureza qualitativa, analisaram as possibilidades de uso do Facebook para a construção do conhecimento, na perspectiva do ensino da Matemática. A pesquisa teve como campo de estudo alunos do $3^{\circ}$ ano do Ensino Fundamental de uma escola da rede pública, no Estado do Rio Grande do Sul. Para o alcance dos resultados, os autores tiveram como principal missão traçar um elo entre "o gosto do aluno pela rede social" e a "corrente teórica da etnomatemática", que objetiva a aprendizagem significativa por meio das vivências dos alunos. Entre os resultados apresentados no resumo do artigo, podemos citar os seguintes:

I - O interesse dos alunos frente ao estímulo da utilização da rede social Facebook como suporte aos conhecimentos matemáticos aumentou significativamente, fortalecendo a participação e o envolvimento nas aulas.

II - A grande maioria dos alunos não apresentavam conhecimentos significativos em relação à rede social Facebook, tanto em suas vivências do cotidiano quanto nas suas contribuições para a proposta pedagógica inserida no ambiente escolar.

III - O desenvolvimento das atividades propostas para a intervenção, baseada nas medidas de comprimento convencionais e arbitrários, junto ao terceiro ano do Ensino Fundamental, ofereceu a oportunidade de aprofundamento do conhecimento da ferramenta Facebook, como suporte para a resolução de situações problema (COSTA; CASTILHO, 2017, p. 2).

Quintanilha (2017) abordaram em seu estudo os impactos provocados pela inserção desenfreada das tecnologias digitais no campo educacional, considerando a necessidade de inovação pedagógica, objetivando a significação concreta do processo de ensino-aprendizagem na perspectiva dos cursos de graduação. Para tal, por meio de uma pesquisa de caráter qualitativo, o pesquisador propôs avaliar se a utilização da plataforma virtual 
do Facebook, no âmbito educacional, apresentava bons resultados, a partir do estudo de campo realizado numa universidade de Salvador.

Torres et al. (2017), por meio de uma abordagem qualiquantitava do tipo estudo de caso, analisaram a experiência da exposição de fotografias e textos por meio da rede social. O trabalho foi desenvolvido na perspectiva de uma linha de pesquisa do programa de pós-graduação stricto sensu, em uma universidade privada no Estado do Paraná. As experiências foram descritas por meio da interação de um grande número de usuários (alunos) que estavam inseridos num grupo virtual dentro da plataforma online. Como resultado, os pesquisadores concluíram que essa rede social tem estado cada vez mais presente em práticas pedagógicas dos professores, possibilitando a criação de um espaço mais dinâmico para interação, compartilhamento de ideias, colaboração, liberdade de expressão e participação nos fóruns de aprendizagem.

Neves (2017) trouxe em seus relatos o uso do Facebook como recurso para a formação continuada para os profissionais formados em Biblioteconomia e Direito. A experiência relatada consiste na criação de uma página na plataforma, com uma linguagem clara, direta e menos técnica.

Tomio et al. (2018) buscaram por meio de seus estudos compreender o desenvolvimento do profissional docente a partir dos sentidos que são atribuídos diante da transposição do que é feito em sala para o espaço virtual, com postagens e compartilhamento de dados, objetivando a divulgação da sua prática educativa. Nessa perspectiva, os autores destacam que:

Essa rede social permite aos professores promoverem 0 entendimento de seu trabalho a partir da reflexão com o outro, incentivarem processos formativos entre pares da escola, darem visibilidade social à sua profissão e elaborarem conhecimentos por meio de interações virtuais (TOMIO et al., 2018, p. 540).

Policarpo e Bergmann (2018), por meio do seu estudo de natureza qualitativa, apresentaram um relato de experiência da integração de mídias 
em aulas de língua espanhola, no âmbito do primeiro ano do Ensino Médio, realizado no colégio de aplicação da Universidade Federal de Santa Catarina (UFSC), utilizando $\bigcirc$ Facebook como principal ferramenta pedagógica.

A motivação para a realização do referido estudo surgiu por meio das experiências desenvolvidas durante o estágio supervisionado, e a plataforma foi utilizada como principal canal de comunicação e compartilhamento de informações, atividades propostas em espaços online (sala de aula invertida). No âmbito da sala de aula invertida, Oliveira (2018) também propôs uma reflexão sobre o uso do Facebook nas aulas de matemática na perspectiva da formação inicial do pedagogo. Trata-se de um relato de experiência a partir do modelo de sala de aula invertida, em que o professor transpõe as atividades de sala de aula para o mundo virtual e digital, propondo uma diferente experiência para com os seus alunos.

\subsection{Ferramentas disponíveis na plataforma do Facebook: como utilizá-las a favor do processo de ensino-aprendizagem?}

Os avanços da web, advindos da revolução da informática e do homem como ser social em constante evolução que se adaptou a uma socialização em rede, bem como do ciberespaço como lócus de interação e compartilhamento de variados tipos de conteúdo, têm a caracterizado como ambiente propício para as atividades humanas nos diferentes contextos. O mundo virtual é concebido como uma extensão do mundo real, não sendo considerado um ambiente imaginário, muito menos algo abstrato, mas que possibilita a efetivação de ações concretas menos que midiáticas, graças às interconexões das máquinas, sobretudo, inicialmente, do computador.

Lévy (2009, p. 92) define o ciberespaço como:

[...] o espaço de comunicação aberto pela interconexão mundial dos computadores e das memórias dos computadores. Essa definição inclui o conjunto dos sistemas de comunicação eletrônicos (aí incluídos os conjuntos de redes hertzianas e telefônicas clássicas), 
na medida em que transmitem informações. Consiste de uma realidade multidirecional, artificial ou virtual incorporada a uma rede global, sustentada por computadores que funcionam como meios de geração de acesso.

Nesse sentido, o Facebook como plataforma virtual, com objetividade e direcionamento pedagógico, torna-se um aliado na construção do processo de ensino-aprendizagem, além de estar condizente com os pressupostos teóricos e práticos que envolvem as novas Tecnologias Digitais da Comunicação e Informação. "Se a proposta é trocar saberes e convivências com os alunos, o Facebook é um recurso adequado, pois faz parte do cotidiano dos jovens, portanto espaço que o aluno vai utilizar com facilidade" (COSTA, 2015, p. 27).

Nesta seção do trabalho, apresentaremos algumas ferramentas disponíveis na plataforma e que podem ser utilizadas com finalidades pedagógicas. Algumas descrições que aqui serão citadas estão condizentes com as pesquisas realizadas no próprio estado da arte. No decorrer desta seção, sentiu-se a necessidade de acessar a plataforma para melhor detalhar algumas potencialidades dessa rede social.

Algumas funções foram destacadas no trabalho de Domingues e Vieira (2016, p. 328):

[...] publicar imagens, vídeos, músicas, textos, entre outros, utilizar as ferramentas de curtir, compartilhar e comentar. Além disso, há possibilidade de bate-papo com uma ou várias pessoas, também é possível criar um grupo (fechado, secreto, aberto) para desenvolver diferentes atividades e entre outros inúmeros recursos disponíveis nessa ferramenta.

Por meio do print screen 5 (figura 02), podemos observar algumas funções que estão acopladas à plataforma do Facebook à disposição dos usuários conectados na rede, que vão desde o simples compartilhamento de conteúdo em texto e imagem até a possibilidade de transmissão síncrona de vídeo ao vivo.

\footnotetext{
5 Nome dado à função de captura de tela nos dispositivos (computadores, notebooks, tablets, smartphones, entre outros).
} 
Figura 02: Print screen capturado pelos autores

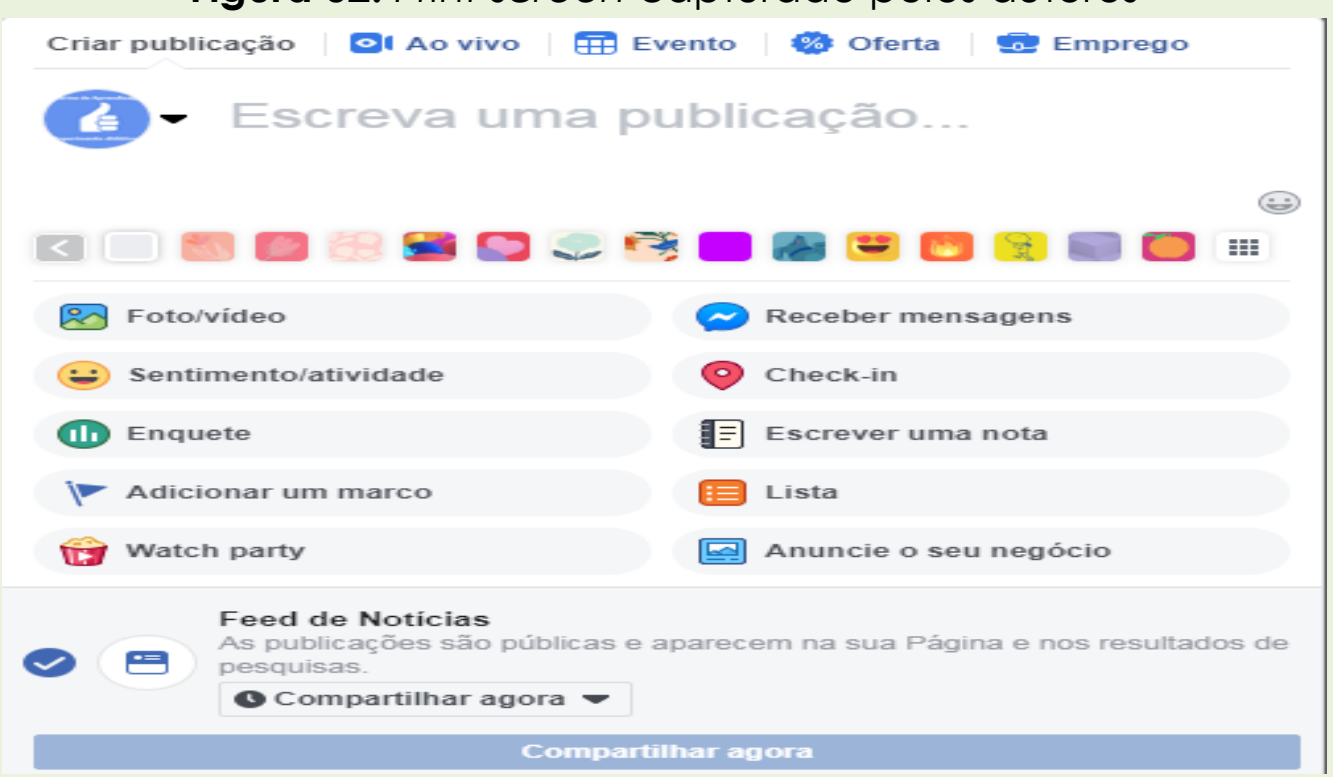

Fonte: www.facebook.com.br.

A plataforma tem como principal função estabelecer comunicações entre os usuários, dessa forma o chat, na perspectiva educacional, tem contribuído significativamente para o "tirar dúvidas" em tempo real ou não, ou seja, há possibilidade de uso tanto online quanto off-line (opção deixar recado) etc., permitindo também a criação de grupo privado de chat, podendo adicionar um grande número de usuários que podem trocar mensagens simultaneamente no mesmo espaço, entretanto isso pode acarretar um desenfreado número de informações, podendo congestionar o fluxo de recebidos e dificultando a compreensão da mensagem principal.

O Facebook pode fornecer aos alunos a oportunidade de apresentar suas ideias, conduzir discussões online e colaborar de forma efetiva. Além disso, o Facebook pode ajudar você, como educador, a se familiarizar com os estilos de aprendizagem digital dos seus alunos (PHILLIPS et al., 2016, p. 03).

Outra ferramenta relevante, que pode ser utilizada a favor do processo de ensino, é o facebooklives, função que permite a transmissão do vídeo em tempo real, podendo agregar também a interação síncrona com outros usuários que estejam conectados à plataforma simultaneamente, ou seja, esse recurso possibilita a execução de uma espécie de videoconferência, 
inclusive, há instituições que se utilizam desse mecanismo para a transmissão de eventos, como congressos, simpósios, mesas redondas etc.

O compartilhamento, talvez, seja a ferramenta mais utilizada pelos usuários dessa rede social, considerando que com esse canal é possível partilhar textos escritos, arquivos de áudio (música, voz), postagem de vídeos, ou links de outros sites. Em outras palavras, a partir do compartilhamento, os usuários que estão conectados podem discernir conhecimento na rede, além de isso contribuir para a divulgação de produções acadêmicas.

Na perspectiva da comunicação no mundo virtual, Levy (2009, p. 83) enfatiza que:

A comunicação por mundos virtuais é, portanto, em certo sentido, mais interativa que a comunicação telefônica, uma vez que implica, na mensagem, tanto a imagem da pessoa como a da situação, que são quase sempre aquilo que está em jogo na comunicação.

De acordo com Policarpo e Bergmann (2018), ao se elaborar e compartilhar atividades no mesmo ambiente promove-se a criação de um espaço propício à reflexão e ao desenvolvimento, permitindo também intervenções pedagógicas que possam nortear essas aprendizagens de forma significativa.

A plataforma também possibilita a criação de eventos, função essa que funciona como uma espécie de lembrete para o usuário; na perspectiva pedagógica, pode ser utilizada para a marcação de atividades síncronas, já que estas ocorrem em tempo real e exigem a participação ativa tanto do professor quanto do aluno. Além disso, é útil para divulgar e receber a confirmação da participação - se há interesse do usuário em estar presente (online) ou se pretende recusar o convite de participação, além de facilitar a marcação de provas, trabalhos.

Inserir comentários nas publicações de outros usuários permite a promoção de um diálogo que pode tender para o crítico, ou até mesmo para o informal, a depender do objetivo do usuário. Isso permite resposta ao 
comentário postado, o que podemos comparar com a ideia de um debate online, além da criação de enquetes, que podem coletar a opinião ou apenas quantificar dados.

A criação de Grupos do Facebook também é um elemento destacável dessa rede social, uma vez que, por meio desse recurso, se pode restringir o acesso, por exemplo, a um grupo de estudos de uma turma da faculdade, haja vista que nesse grupo somente poderão visualizar as postagens os alunos que foram inseridos pelo administrador. Essa função permite reunir alunos e professores dentro de um mesmo ambiente virtual.

Nessa perspectiva de grupos virtuais de Facebook ou comunidades de aprendizagem, Costa e Castilho (2017, p. 8-9) destacam que:

[...] O professor pode antecipar os assuntos a serem abordados na sala de aula; estimular o aluno a pesquisar sobre esses temas a fim de promover uma discussão mais interessante, tanto no site da rede social quanto na sala de aula, sobre o que pretende ensinar; propor atividades complementares sobre os assuntos, sanando dúvidas que porventura possam surgir durante 0 processo de ensinoaprendizagem; permitir o acesso tanto dos educandos quanto do professor ao conteúdo em discussão no grupo; acompanhar o trânsito dos alunos no grupo e intervir sempre que necessário [...].

A própria plataforma permite a criação de conteúdo e a criação de novas páginas dentro de um grupo. Podem ser colocados assuntos diversos que ficam armazenados por tempo indefinido. Exemplos: Notas de exames, resumos de aula, planos de ensino. Já os serviços de localização podem auxiliar na compreensão de fenômenos geográficos, assim como aprimorar a utilização de escalas, podendo facilitar na aprendizagem de cartografia e geografia (TONETTO; TONINI, 2015).

Com base nas informações sobre os recursos observados e a dinâmica social do Facebook, foi possível a construção de um quadro (quadro 02) com vantagens e desvantagens referentes ao uso dessa plataforma como recurso pedagógico na educação. 
Quadro 02: vantagens e desvantagens do uso do Facebook na Educação.

\begin{tabular}{|l|l|}
\hline \multicolumn{1}{|c|}{ Vantagens } & \multicolumn{1}{|c|}{ Desvantagens } \\
\hline $\begin{array}{l}\text { Possibilidade de realizar tarefas síncronas } \\
\text { e assíncronas. }\end{array}$ & $\begin{array}{l}\text { Não há possibilidade de trabalhar off- } \\
\text { line. }\end{array}$ \\
\hline $\begin{array}{l}\text { Compartilhamento instantâneo com o } \\
\text { maior número de pessoas possível por } \\
\text { chat, ou pelo feed. }\end{array}$ & $\begin{array}{l}\text { Bombardeamento de mensagens que } \\
\text { podem atrapalhar a compreensão do } \\
\text { assunto principal. }\end{array}$ \\
\hline $\begin{array}{l}\text { Criação de página oficial ou grupo } \\
\text { online de estudos. }\end{array}$ & $\begin{array}{l}\text { Notificações indesejadas direcionam os } \\
\text { alunos para outras postagens. }\end{array}$ \\
\hline $\begin{array}{l}\text { Professor norteia o aluno para um jogo } \\
\text { educativo. }\end{array}$ & $\begin{array}{l}\text { Convite de um "amigo virtual" para um } \\
\text { jogo não educativo. }\end{array}$ \\
\hline $\begin{array}{l}\text { Tanto o professor quanto os alunos } \\
\text { podem compartilhar as principais notícias } \\
\text { e informações que aconteceram } \\
\text { durante o dia. }\end{array}$ & $\begin{array}{l}\text { Qualquer pessoa pode publicar } \\
\text { qualquer assunto (tendência de } \\
\text { compartilhamento de informações } \\
\text { falsas). }\end{array}$ \\
\hline $\begin{array}{l}\text { Diversidade de idiomas, tendo a opção } \\
\text { de tradução em suas postagens. }\end{array}$ & $\begin{array}{l}\text { Como plataforma de interação } \\
\text { informal, inúmeros usuários fazem uso } \\
\text { de linguagem inadequada e ofensiva. }\end{array}$ \\
\hline $\begin{array}{l}\text { Integração com outras plataformas e } \\
\text { serviços (jogos, páginas, sites, blogs, } \\
\text { aplicativos). }\end{array}$ & $\begin{array}{l}\text { Devido s essa sua vasta integração } \\
\text { com outras interfaces, facilita a } \\
\text { proliferação de vírus, que podem } \\
\text { danificar aparelhos e espalhar } \\
\text { informações pessoais. }\end{array}$ \\
\hline
\end{tabular}

Fonte: Os autores.

Talvez, devido a esses fatores, o uso dessa rede ainda na educação esteja um pouco restrito, como afirmam Dias e Ignácio (2014, p. 07):

[...] Aqui no Brasil, em muitas escolas, o "Facebook" é bloqueado. Ainda encontramos falta de infraestrutura para o uso da "internet" e muita resistência dos responsáveis dos estudantes e dos administradores das escolas para 0 uso das redes sociais como ferramenta pedagógica.

Diante das ferramentas que foram expostas, cabe ressaltar que elas, assim com o Facebook, não foram criadas com finalidades educacionais, tratando-se apenas de recursos para facilitar a comunicação. Entretanto, com objetividade didática, essas ferramentas podem se tornar pedagógicas, cabendo ao professor mediar e nortear os alunos quanto ao uso dessa plataforma a favor da aprendizagem. Talvez esse seja o maior desafio, considerando o bombardeamento de informações que chegam ao site a cada instante; assim como os desafios enfrentados pelos docentes em

Revista Exitus, Santarém/PA, Vol. 10, p. 01 - 28, e020031, 2020. 
inserir recursos tecnológicos no contexto escolar, por diversos fatores, como, por exemplo, manipulação dessas mídias, falta de recursos e até mesmo falta de conhecimento em relação a saber utilizar uma rede social como ferramenta de ensino, como destacam Ferrete e Santos (2020, p. 14):

\begin{abstract}
Educar na era digital tem se caracterizado como grande desafio que vem sendo enfrentado pelos docentes, em sua maioria, imigrantes tecnológicos, não foram instruídos a utilizar a tecnologia como ferramenta de trabalho, por outro lado, os alunos trazem consigo uma bagagem e apropriação tecnológica que impressiona a comunidade escolar, são hábeis com esses recursos, utilizam de forma natural, desvendam o mundo navegando pela internet, estão extremamente conectados em rede, e não sentem dificuldades em viver no mundo digital.
\end{abstract}

Sampaio e Leite (2008) abordaram sobre a relevância de uma alfabetização tecnológica do professor no sentido de uma preparação pedagógica que extrapole o uso de ferramentas para o trabalho docente e a comunicação, mas no manuseio e na interação com as informações disponíveis na rede. Nesse mesmo sentido, Moran et al. (2000) enfatizam que o professor precisa buscar um ponto de equilíbrio e adequação quanto à inserção das tecnologias no ensino, que ampliem essa utilização e que aprendam a dominar a comunicação interpessoal e grupal (comunidades virtuais), além de aprimorar a comunicação audiovisual/telemática.

Essa ausência da abordagem tecnológica tanto nos cursos de formação de professores em nível das licenciaturas quanto nos cursos de formação continuada dificulta o trabalho pedagógico; as aulas permanecem ociosas, com pouca produtividade e interação por parte dos alunos (nativos digitais), que aprendem de formas diferentes e traçam conexões virtuais e buscas no ciberespaço que os direcionam a aprendizagem autônoma, quando são motivados a buscar.

\title{
4 CONSIDERAÇÕES FINAIS
}

O Facebook, como rede social de maior alcance em massa, até o presente momento, tem se caracterizado como amplo espaço para partilha 
de informações, experiências e aprendizagens, mesmo tendo como foco principal o entretenimento. Entretanto, no contexto da cibercultura (cultura digital e contemporânea), o cenário educacional brasileiro caminha a passos lentos em busca da inclusão digital no âmbito escolar. Isso ocorre seja por falta de recursos tecnológicos nas unidades escolares, por problemas envolvendo a formação de professores que não tiveram preparação para lidar com as novas TDIC ou pela qualidade do acesso à internet que é disponibilizada para as escolas públicas.

Diante dessas barreiras oriundas do sistema educacional público e diante das produções acadêmicas disponíveis no portal da CAPES, foi possível perceber um maior nível de engajamento por parte dos docentes ao compararmos com os estudos realizados anteriormente, no que diz respeito à inserção de redes sociais a favor do ensino, possibilitando a construção da aprendizagem por meio de um espaço virtual. Isso pode interligar outros espaços/cenários online, considerando como o Facebook permite que o usuário estabeleça conexões com outras aplicações (jogos, sites, blogs, aplicativos).

Integrados e incluídos em comunidades virtuais, os sujeitos da aprendizagem (professores e alunos) tendem a efetivar a construção de uma rede de conhecimentos. Os professores serão os mediadores da aprendizagem, serão os responsáveis pelas mobilizações no grupo (fechado ou aberto) ou na página (pública ou privada) sempre que acharem necessário, e o ambiente necessariamente precisa ser inovador, dinâmico e atrativo.

É preciso considerar esses novos espaços como oportunidades de aprendizagem em rede, uma nova alternativa capaz de substituir ou complementar os Ambientes Virtuais de Aprendizagem que geralmente são utilizados justamente por terem características e funções idênticas, mas que possuem propósitos diferentes, podendo ser utilizados para as mesmas finalidades educacionais. 
Vale ressaltar a necessidade de alinhamento entre os objetivos de aprendizagem estabelecidos pelo docente, seu plano de ação/plano de aula e a plataforma virtual. Os objetivos precisam ser claros e coesos para que os alunos possam ser norteados diante do ciberespaço, de modo que não fiquem online e dispersos ou simplesmente sejam bombardeados por informações superficiais que não contribuirão de forma alguma para o seu desenvolvimento.

\section{REFERÊNCIAS}

BARROS, D. M. V.; SPILKER, M. J. Ambientes de Aprendizagem Online: contributo pedagógico para as tendências de aprendizagem informal.

Revista Contemporaneidade Educação e Tecnologia. v. 01, n. 03, abril 2013. Disponível em: <https://repositorioaberto.vab.pt/handle/10400.2/2812>. Acesso em: 08 ago. 2019.

CORREIA, P. M. A. R.; MOREIRA, M. F. R. Novas formas de comunicação: história do Facebook - Uma história necessariamente breve. Revista Alceu, $v$. 14, n. 28, p. 168-187, junho 2014. Disponível em: <http://revistaalceu.com.pucrio.br/media/alceu\%2028\%20-\%20168-187.pdf>. Acesso em: 18 abr. 2019.

COSTA, L. A. C. da; CASTILHOS, A. da C. Contribuições do Facebook para a alfabetização matemática no $3 .^{\circ}$ ano do ensino fundamental. Revista Observatório, Palmas, v. 3, p. 274-300, agosto 2017. Disponível em: <http://hdl.handle.net/1822/43426>. Acesso em: 08 maio 2019.

COSTA, Ú, B, da. O Facebook como ferramenta pedagógica nas aulas de Língua Inglesa. Trabalho de conclusão de curso, Universidade Federal do Rio Grande do Sul, 2015. Disponível em: <https://www.lume.ufrgs.br/bitstream/handle/10183/133736/000982508.pdf?s equence=1>. Acesso em: 21 fev. 2019.

DIAZ, M. D. C. da C.; IGNÁCIO, E. M. Facebook: uma ferramenta pedagógica? Explorando as possibilidades educacionais da rede social. SiteCETIC. br. Disponível em: <https://cetic.br/>. Acesso em: 21 fev. 2019.

DOMINGUES, A. M.; VIEIRA; M. A. Utilização da rede social facebook em sala de aula. Conexões Culturais - Revista de Linguagens, Artes e Estudos em Cultura. v. 02, n. 01, p. 327-329, 2016. FACEBOOK. Página oficial do Facebook. Disponível em: <https://www.facebook.com/pg/FacebookBrasil/about/?ref=page_internal>. Acesso em: 18 abr. 2019. 
FERREIRA, G. M. dos S.; CAMPOS, A. F. Facebook e recursos educacionais abertos na formação de pesquisadores em educação: percepções e reflexões. Revista EFT. Disponível em:

<http://www.eft.educom.pt/index.php/eft/article/viewFile/380/198>. Acesso em: 7 maio 2019.

FERREIRA, N. S. de A. As pesquisas denominadas "estado da arte". Revista Educação \& Sociedade, n. 79, agosto 2002. Disponível em: <http://www.scielo.br/pdf/es/v23n79/10857.pdf>. Acesso em: 16 jul. 2019.

FERRETE, A. A. S. S.; SANTOS, W. L. INCLUSÃO DIGITAL NA ESCOLA: Uma análise dos relatos de experiências dos professores da educação básica no município de Jeremoabo-BA. Revista Rios (UniRios), Paulo Afonso-BA, 2020.

FRANCISCO, C.; OLIVEIRA, R. Práticas pedagógicas digitais: o Facebook e a sala de aula invertida na formação dos alunos do ProfLetras. Revista Odisseia, v. 1, n. 2, p. 48-61, 6 set. 2016.

LÉVY, P. Cibercultura. São Paulo: Ed. 34, 2010.

MORAN, J. M. et al. Novas tecnologias e mediação pedagógica. 6. ed. Campinas: Papirus, 2000.

NEVES, S. Biblio Juris - Biblioteconomia e Direito: o uso do Facebook na educação continuada. Cadernos de Informação Jurídica, Brasília, v. 4, n. 2, p. 43-54, jul./dez. 2017. Disponível em: <http://www.brapci.inf.br/index.php/res/v/38598>. Acesso em: 16 ago. 2019.

OLIVEIRA, L. R. Mediação docente e distância transacional: uso do Facebook num mestrado em regime misto (B-learning). Revista e-Curriculum, São Paulo, v. 14, n. 04, p. 1484-1498, out./dez. 2016. Disponível em: <https://revistas.pucsp.br/curriculum/article/view/28477/21887>. Acesso em: 16 ago. 2019.

OLIVEIRA, C. A. de. Sala de aula invertida nas aulas de matemática na formação do pedagogo em tempos de cibercultura. Revista Prática Docente. v. 3, n. 1, p. 125-139, jan./jun. 2018. Disponível em:

<https://www.researchgate.net/publication/326002553C>. Acesso em: 08 maio 2019.

PERRENOUD, P. As 10 competências para ensinar. Porto Alegre: Artmed, 2000.

PHILLIPS, L. F.; BAIRD, D. M. A.; FOGG, B. J. Facebook para educadores. Disponível em:

<https://educotraducoes.files.wordpress.com/2012/05/facebook-paraeducadores.pdf>. Acesso em: 22 jun. 2019. 
POLICARPO, K. M. de S.; BERGMANN, J. C. F. Prof., posso usar o facebook?: experiência de integração de mídia social em classe. Rev. Entre Línguas, Araraquara, v. 4, n. 1, p. 31-42, jan./jun. 2018. Disponível em: <https://periodicos.fclar.unesp.br/entrelinguas/article/view/10918>. Acesso em: 10 maio 2019.

QUINTANILHA, L. F. Inovação pedagógica universitária mediada pelo Facebook e Youtube: uma experiência de ensino-aprendizagem direcionado à geração-Z. Educar em Revista, Curitiba, Brasil, n. 65, p. 249-263, jul./set. 2017. Disponível em: <http://www.scielo.br/pdf/er/n65/0104-4060-er65-00249.pdf>. Acesso em: 09 maio 2019.

RABELLO, C. R. L. R.; TAVARES, K. C. do A. As tecnologias digitais no ensino e aprendizagem de línguas. VEREDAS ON LINE - AS TECNOLOGIAS DIGITAIS NO ENSINO E APRENDIZAGEM DE LÍNGUAS - 2016/1, p. 124-136. Disponível em: <http://www.ufjf.br/revistaveredas/files/2016/08/Redes-sociais-eaprendizagem-no-ensino-superior_artigo-8.pdf>. Acesso em: 08 maio 2019.

SAMPAIO, M. N; LEITE, L. S. Alfabetização tecnológica do professor. 6. ed. Petrópolis-RJ: Vozes, 2008.

SANTOS, W. L.; SANTOS, E. F. dos. A docência no ensino superior e sua relação pedagógica na EAD. Revista Rios (UniRios), Paulo Afonso-BA, 2017.

SANTOS, R. da S.; OLIVEIRA, R. V.; SILVA, E. G.s da. Utilização de grupos de rede social como ferramenta didática no curso de engenharia de produção. Anais do COBENGE, 2014. Disponível em <http://www.abenge.org.br/cobenge/arquivos/5/Artigos/129134.pdf>. Acesso em: 08 maio 2019.

SILVA, R. B. da; BENTOS, A. de M.; BALBUENA, C. R. M. A Construção do Conhecimento via Facebook: análise de um projeto de ensino de geografia. Revista: EaD\& Tecnologias Digitais na Educação, Dourados, MS, v. 3, n. 4, 2015. Disponível em:

<https://periodicos.feevale.br/seer/index.php/revistapraksis/article/viewFile/1 095/1549>. Acesso em: 08 maio 2019.

TEIXEIRA, C. A. A origem do Facebook. Jornal O Globo. Disponível em: <https://oglobo.globo.com/economia/a-origem-do-facebook-4934191>. Acesso em: 18 abr. 2019.

TOMIO, D.; BIHRINGER, K. R. B. B.; TRIGO, L. K. L. Professor@ facebookeir@ e seu desenvolvimento profissional docente em um contexto informal. Revista

Práxis Educativa, Ponta Grossa, v. 13, n. 2, p. 540-554, maio/ago. 2018. 
Disponível em: <http://www.revistas2.uepg.br/index.php/praxiseducativa>. Acesso em: 10 maio 2019.

TONETTO, É. P.; TONINI, I. M. Ensinar e aprender geografia com/nas redes sociais. Revista Gira Mundo, Rio de Janeiro, v. 2, n. 3, p. 87-96, jan./jun. 2015. Disponível em:

<http://www.cp2.g12.br/ojs/index.php/GIRAMUNDO/article/view/221>. Acesso em: 10 maio 2019.

TORRES, P. L.; BOARON, D. C.; KOWALSKI, R. P. G. Exposição fotográfica e uso do Facebook para fins educacionais. Holos, Natal, v. 1, p. 415-428, 2017.

ÚNICO Agencia Digital. Você sabe quais são as redes sociais mais usadas no mundo?. Disponível em: <https://www.agenciaunico.com.br/blog/vocesabe-quais-sao-as-redes-sociais-mais-usadas-no-mundo/>. Acesso em: 18 abr. 2019.

Recebido em: 16 de agosto de 2019 Aprovado em: 11 de fevereiro de 2020 